Article

\title{
Generalized storage-yield-reliability relationships for sizing and assessing shopping centre rainwater harvesting systems in South Africa.
}

\author{
Ndiritu John ${ }^{1}$, Moodley Yashiren ${ }^{2}$ and Guliwe Mondli ${ }^{3}$ \\ 1 School of Civil and Environmental Engineering, University of the Witwatersrand, Johannesburg, South \\ Africa; John.Ndiritu@wits.ac.za \\ 2 School of Civil and Environmental Engineering, University of the Witwatersrand, Johannesburg, South \\ Africa, now at Arup Consulting, South Africa; Yashiren.Moodley@gmail.com \\ 3 School of Civil and Environmental Engineering, University of the Witwatersrand, Johannesburg, South \\ Africa, now at Knight Piesold Consulting Engineers, South Africa; Guliwe.m1@gmail.com
}

\begin{abstract}
The objective of this study was to develop guidelines for rainwater harvesting system sizing of shopping centres in South Africa. Three generalized dimensionless relationships relating rainwater supply and demand to tank size, yield and reliability were developed based on 101 years long daily time step simulations of rainwater harvesting of 19 shopping centres located in four regions. Daily rainfalls were obtained from nearby rainfall stations and daily non-potable demands were based on the size of the retail area. The simulations revealed within-year storage behaviour with considerable variation of the yield specified as the number of days for which demand was met each year. The Weibull plotting position formula was applied on the time series of yields to obtain yield-reliability relationships. Simulation results of the hydrologically optimum systems were used to develop two of the generalized relationships and an additional one based on the dependence of the slope of the reliability - yield plots on the optimum yield was formulated to enable analysis of hydrologically non-optimal systems. Most of the relationships fitted best to the non-linear power law form with high correlation coefficients averaging 0.92 and ranging from 0.82 to 1.00 . The application of the models for tank sizing and assessing system performance is demonstrated.
\end{abstract}

Keywords: rainwater harvesting; yield, reliability; plotting positions; generalization; optimized hydrologic design; shopping centres

\section{Introduction}

Globally, available water resources are being outstripped by the escalating water demand which is growing at an unprecedented rate [1] and future economic growth and development will consequently be constrained [2]. Pinzon [3] has highlighted the growing evidence of water scarcity worldwide and the need for cooperation and integration to ensure sustainable, efficient and equitable water resources management. With the large population growth in urban areas and changing water use habits, there is an ever-increasing demand for water in urban areas [4] and it is probable that rain water harvesting could help to alleviate this strain on current resources. Rainwater harvesting is relatively cheaper and simpler to install, operate and maintain and is more environmentally friendly than many other water resource developments. Although rainwater has been found to not always not meet drinking water standards $[5,6,7,8,9]$, the quality of rainwater is usually superior to surface water (from rivers, dams or lakes) and groundwater that may have been subjected to contamination [10]. Sazakli et al. [11] report that rainwater from rooftops generally meets international drinking water quality standards. 
South Africa is a water-scarce country with a mean annual precipitation (MAP) of $465 \mathrm{~mm}$ which is unevenly distributed in space and time. Rainwater harvesting use in South Africa is low $[4,12,13,14]$ and its potential as a water source therefore needs to be comprehensively assessed. Rainwater harvesting is likely to have more potential in situations where large areas of rain water collection are available. Ndiritu et al. [15] analyzed the rainwater harvesting potential of 32 schools in South Africa and found that in every year, between 42 and 132 days of the daily school supply could be provided at a reliability of $90 \%$. Shopping centres generally have large roof areas and could therefore also have significant rain water harvesting potential. According to Prinsloo [16] there are 1785 shopping centres larger than $2000 \mathrm{~m}^{2}$ in area in South Africa and the number is expected to increase in the future. Although some shopping centres have installed rain water harvesting systems this is not widespread. This study evaluates the rainwater harvesting potential of selected shopping centres in different regions of South Africa and uses the results of this assessment to develop generalized guidelines for sizing and evaluating the performance of rainwater harvesting systems.

\section{Selection of Malls and Data Acquisition}

Rainfall distribution in South Africa exhibits high spatial variability and the selection of shopping centres was done bearing this in mind. The aim was however not exhaustive coverage of all rainfall zones within the country and the following four regions were considered as reasonably representative and were selected for analysis; Kwa Zulu Natal, Gauteng, Limpopo and Western Cape. Prinsloo [17] classified shopping centres according to their floor area as; Neighbourhood centres $\left(5000-12000 \mathrm{~m}^{2}\right)$, Community centres $\left(12000-30000 \mathrm{~m}^{2}\right)$, Large community/small regional centres $\left(30000-50000 \mathrm{~m}^{2}\right)$, Regional centres $\left(50000-100000 \mathrm{~m}^{2}\right)$ or Super regional centres $(>100000$ $\mathrm{m}^{2}$ ). It was decided to select one shopping centre from each category and region so as to assess rainwater harvesting system across the range of sizes of shopping centres. Selecting 5 shopping centre categories in 4 regions would have provided 20 shopping centres but no super regional centre could be identified in the Limpopo region and a total of 19 shopping centres were therefore selected for analysis.

The rainfall database developed by Lynch [18] was used to find the rain gauge station with a long and reliable daily rainfall record closest to each shopping centre. All the selected rainfall stations had 101 years of daily rainfall data for the period 1900 - 2000 some of which had been patched in the development of the database. Table 1 shows the shopping centres selected for analysis, the respective rain gauge stations and the distances from the shopping centres to the rain gauge stations. No information on demand was availed by the shopping centres and CSIR [19] proposed a demand of 4 $\mathrm{m}^{3} / \mathrm{m}^{2}$ of floor area/year for South Africa. A study on 40 shopping centres of varying sizes in Western Australia [20] obtained highest demands of 2.828, 3.141, 1.347, and $1.383 \mathrm{~m}^{3} / \mathrm{m}^{2} /$ per year for neighbourhood centres, large community/small regional centres, regional centres, and super regional centres respectively. Since these demands were based on detailed field measurements and the characteristics that determine demand in Western Australia malls are not likely to be substantially different to those in South Africa, they were adopted for analysis in this study. For community centres, the average overall demand of $2.18 \mathrm{~m}^{3} / \mathrm{m}^{2} /$ per year obtained by Saunders [20] was adopted. 
Table 1. Selected shopping centres and rainfall stations.

\begin{tabular}{|c|c|c|c|c|c|}
\hline Region & Mall & $\begin{array}{l}\text { Retail area } \\
\qquad\left(\mathrm{m}^{2}\right)\end{array}$ & $\begin{array}{l}\text { Roof area } \\
\left(\mathrm{m}^{2}\right)\end{array}$ & $\begin{array}{c}\text { Rainfall } \\
\text { station No. }\end{array}$ & $\begin{array}{l}\text { Distance } \\
\text { from mall } \\
\quad(\mathbf{k m})\end{array}$ \\
\hline \multirow{5}{*}{ Gauteng } & Sandton City & 128000 & 83472 & $0476093 \mathrm{~W}$ & 6.67 \\
\hline & South Gate Mall & 89700 & 45349 & $0476044 \mathrm{~W}$ & 6.24 \\
\hline & Norwood Mall & 32344 & 32194 & $0476129 \mathrm{~W}$ & 0.43 \\
\hline & Braamfontein Centre & 21309 & 3416 & $0475881 \mathrm{~W}$ & 0.97 \\
\hline & Grayston Centre & 5000 & 4198 & $04760093 \mathrm{~W}$ & 5.68 \\
\hline \multirow{5}{*}{$\begin{array}{l}\text { Cape } \\
\text { Town }\end{array}$} & Canal Walk & 141000 & 26082 & $0020896 \mathrm{~W}$ & 4.38 \\
\hline & Tygervally Centre & 90000 & 55403 & $0021230 \mathrm{~W}$ & 4.74 \\
\hline & Willow Bridge & 40051 & 23390 & $0021230 \mathrm{~W}$ & 3.95 \\
\hline & Howard Centre & 15000 & 14052 & $0021055 \mathrm{w}$ & 2.88 \\
\hline & Capricon Square & 5889 & 6374 & $0020839 \mathrm{~W}$ & 13.11 \\
\hline \multirow{4}{*}{ Limpopo } & Mall of the North & 75000 & 35199 & $0678023 \mathrm{~W}$ & 1.26 \\
\hline & Savanah Mall & 37000 & 17880 & $0677834 \mathrm{~W}$ & 2.15 \\
\hline & Limpopo Mall & 27766 & 7446 & $0677834 \mathrm{~W}$ & 1.81 \\
\hline & Cycad Shopping Centre & 12000 & 5267 & $0677834 \mathrm{~W}$ & 0.94 \\
\hline \multirow{5}{*}{$\begin{array}{l}\text { Kwa } \\
\text { Zulu } \\
\text { Natal }\end{array}$} & Gateway Mall & 180000 & $123498 / 73313^{*}$ & $0241103 \mathrm{~W}$ & 0.97 \\
\hline & Liberty Midlands Mall & 75000 & $74702 / 55241^{*}$ & $0239605 \mathrm{~W}$ & 3.21 \\
\hline & Musgrave Centre & 39886 & 20058 & $0240738 \mathrm{~W}$ & 8.36 \\
\hline & Phoenix Plaza & 24162 & $29307 / 18070^{*}$ & $0241042 \mathrm{~W}$ & 2.72 \\
\hline & Granada Square & 5818 & 2097 & $0241103 \mathrm{~W}$ & 2.15 \\
\hline
\end{tabular}

\section{Simulation Analysis}

The rainwater harvesting potential of shopping centres was assessed by daily simulation of system behaviour for a specified storage capacity assuming the tank was initially empty. McMahon and Adeloye [21] highlight the advantages of this approach for storage-yield analysis and the method has been applied for rainwater harvesting analysis in several studies [15,22,23,24,25]. From the simulation, a time series of the daily levels of water supply was obtained and used to assess system performance. Figure 1 illustrates the simulation and equations 1 to 4 describe the mass balance computations applied. The yield-after-spillage approach was applied as it is more realistic since typically, demand spreads over a larger period of the day than rainfall and spillage and the tank is therefore unlikely to be full (rather than filled to capacity) at the start of the day. This approach obtains slightly lower yields than yield-before-spillage approach and has been applied in other studies [26,27]. A water collection efficiency $(\boldsymbol{\eta})$ of $80 \%$ determined from field experiments in South Africa [28] and also applied in other studies $[15,29,30]$ was adopted. As equation 3 informs, complete supply of the demand was assumed as long as water was available in storage. This was considered realistic as water would be obtained from the municipal supply once the rainwater harvesting storage was exhausted and hedging was therefore not incorporated.

Several methods can be applied to quantify various aspects of hydrologic performance [31] and the selection here was guided by the need for the measure to be widely understandable and to easily lend itself to the assessment of reliability. Trial simulation runs indicated that the rainwater harvesting systems could not meet the total water demand for most of the shopping centres and it was decided to assess their ability to supply the non-potable demand as this typically requires 
minimal treatment. For the 40 shopping centres analyzed by Saunders [20] an average of $45 \%$ of the total demand was for non-potable use (cooling towers for air conditioning, toilets, urinals and cleaning) and this proportion was adopted. The trial simulations runs also revealed that the rainwater harvesting systems mainly exhibited within-year storage behaviour (Figure 2) with the storage emptying in all (or most) of the years for some days in during the dry season. An exception to this was found for 3 of the malls in the Kwa Zulu Natal region (Gateway, Liberty and Phoenix) where the average available water supply exceeded average demand. Over-year storage behaviour with large storage carryover across years (Figure 3) was observed in these cases and it was found possible to meet the demand throughout the simulation periods if very large storages were installed (e.g. 900000 $\mathrm{m}^{3}$ for Gateway shopping centre). A reliability-based analysis approach for multi-year storage requires the use of a large number simulations using stochastically generated hydro-climatic data and stochastic over-year storage systems analysis methods are reasonably well developed and widely applied in South Africa [32,33,34]. It was therefore considered appropriate to confine the current analysis to within-year storage behaviour and this was accomplished by reducing the effective roof areas for the 3 centres in Kwa Zulu Natal to obtain supply to demand ratios less than unity. With all the systems now exhibiting within-year storage behaviour, a single simulation run of 101 years was considered to provide 101 independent within-year yields and these were regarded as adequate for a realistic assessment of reliability of yield. Several studies have applied the proportion of demand met in the complete simulation period (volumetric reliability) as the measure of performance $[26,27,35]$ but this measure does not inform about the variability of performance within the simulation period. For regions that exhibit large inter-annual rainfall variability as South Africa, it is imperative to incorporate this variability for realistic system sizing and performance assessment.

The expected number of days that the release from the tank would meet the demand in each year was considered to be widely understandable and was adopted as the measure of system performance. For each year of the simulation, the number of days that the release $\boldsymbol{R}_{e}(\boldsymbol{t})$ equaled the demand $\boldsymbol{D}(t)$ was obtained and the Weibull plotting position formula was then applied on the time series of the number of days of supply to determine the expected number of days of supply for specified reliabilities. This was done by ranking the number of days of supply from the highest to the lowest and specifying the probability $p$ that the system will supply the number of days ranked $m$ as $p=m /(n+1)$ where $n$ is total number of years of simulation. This model was formulated by Weibull [36] and more recently proposed as more valid than other plotting position formulae [37]. The use of alternative plotting position formulae as proposed by Cunnane [38] in the current analysis did not result in any significant differences in computed reliabilities. The simulations were carried out for increasing tank sizes until the yield levelled off to the highest value at a given reliability for the given roof area and rainfall input. The minimum tank sizes that achieved the highest yield were considered as hydrologically optimum for the specific reliability. Probabilistic water resource systems analysis in South Africa typically applies reliabilities in the range 90-99\% [32] and this study applied a slightly higher range of $85 \%$ to $99 \%$.

$$
\begin{aligned}
& S_{r}(t)=S(t)+\eta R(t) A \\
& \text { if } S_{s}(t)>C \text { then } S_{r}(t)=C \\
& R_{e}(t)=\begin{array}{cc}
D_{t} \quad \text { if } S_{s}(t) \geq D_{t} \\
S_{s}(t) \quad \text { if } S_{s}(t)<D_{t}
\end{array} \\
& S(t+1)=S_{s}(t)-R_{e}(t)
\end{aligned}
$$

where $S(t), S_{r}(t)$ and $S_{s}(t)$ is the volume of water in storage in period $t$ at the start of the day, at end of the rainfall event and at the end of spillage respectively, $C$ is the live storage capacity of the tank, $R_{e}(t)$ is the volume of water released to meet the demand in period $t, D(t)$ is the volume of water 
demanded in period $t, \eta$ is the water collection efficiency, $A$ is the vertical projection of the effective roof area, and $R(t)$ is the rainfall intensity in period $t$.

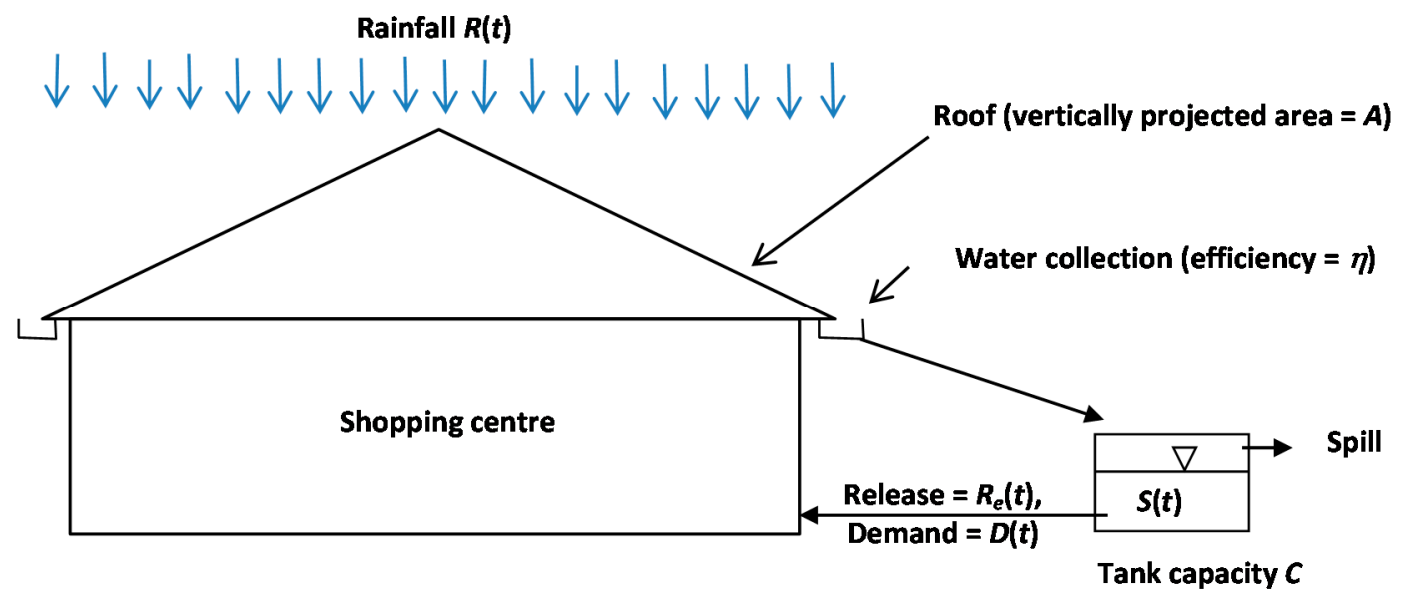

Figure 1 Rainwater harvesting system simulation components

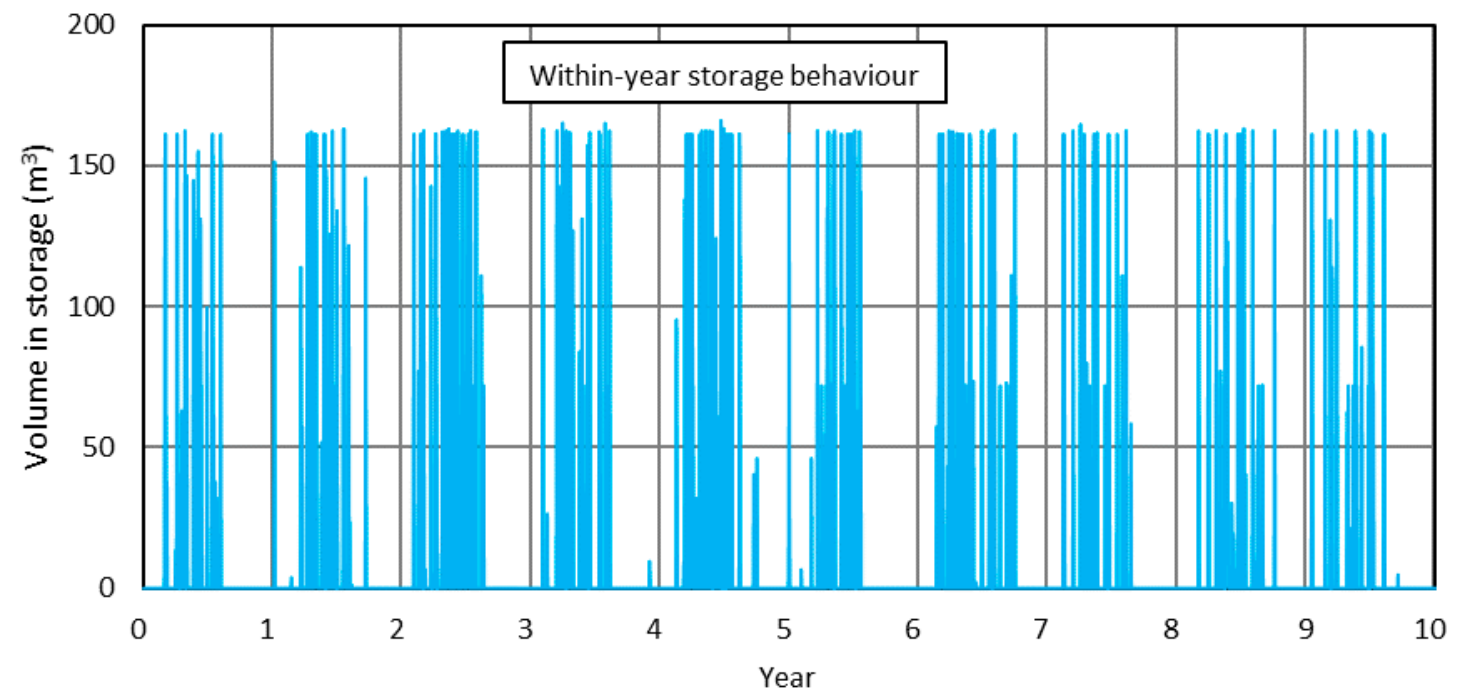

Figure 2 Illustration of within-year storage behaviour

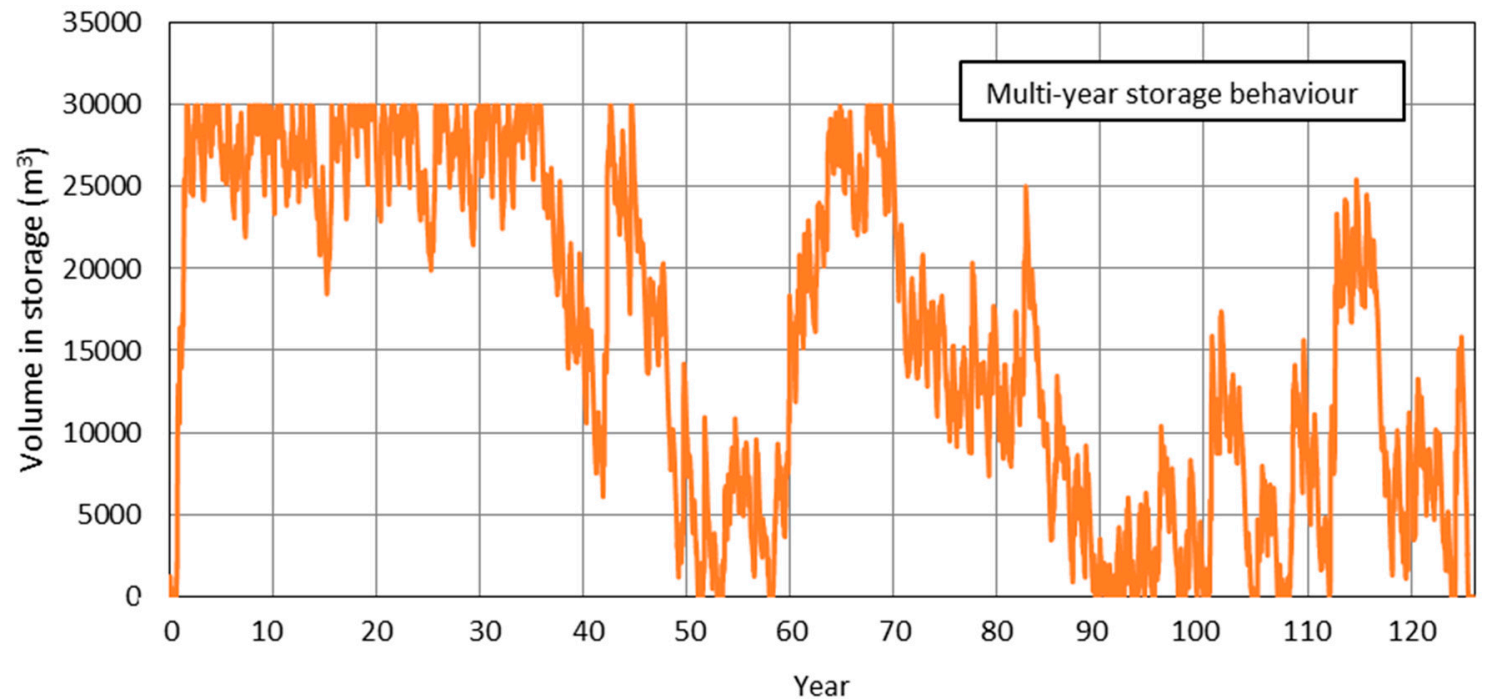

Figure 3 Illustration of over-year storage behaviour 


\section{Results of Simulation}

Yield-reliability curves for a range of tank sizes up to and exceeding the optimum tank size were plotted for each shopping centre. Figure 4 presents this plot for one of the 19 centres and shows that for this centre, tank sizes of $6800 \mathrm{~m}^{3}$ and $8000 \mathrm{~m}^{3}$ gave identical yield-reliability plots. Plots of tank size versus yield (the expected number of days of supply) for various reliabilities as illustrated in Figure 5 for one shopping centre helped identify the optimal tank sizes more easily. Figure 5 shows that for Sandton city mall, the optimal tank sizes at 99, 98 and 95\% reliability were 1600, 2000 and $5600 \mathrm{~m}^{3}$ respectively, while a size of $6800 \mathrm{~m}^{3}$ is optimal at 90 and $85 \%$ reliability.

At reliabilities of 85, 90, 95, 98 and $99 \%$, the optimal tank size, the associated expected yield were determined. Since the yield (expected number of days of supply per year) obtained the optimal tank size (storage) can only be increased by reducing the reliability, the three values (yield, reliability and storage) therefore made the hydrologically optimum combination for the specific supply to demand ratio applying to the shopping centre. Table 2 presents the results of the hydrologically optimum combinations for the 19 shopping centres. This Table reveals that rainwater harvesting could be a viable source of water for some but not all the shopping centres.

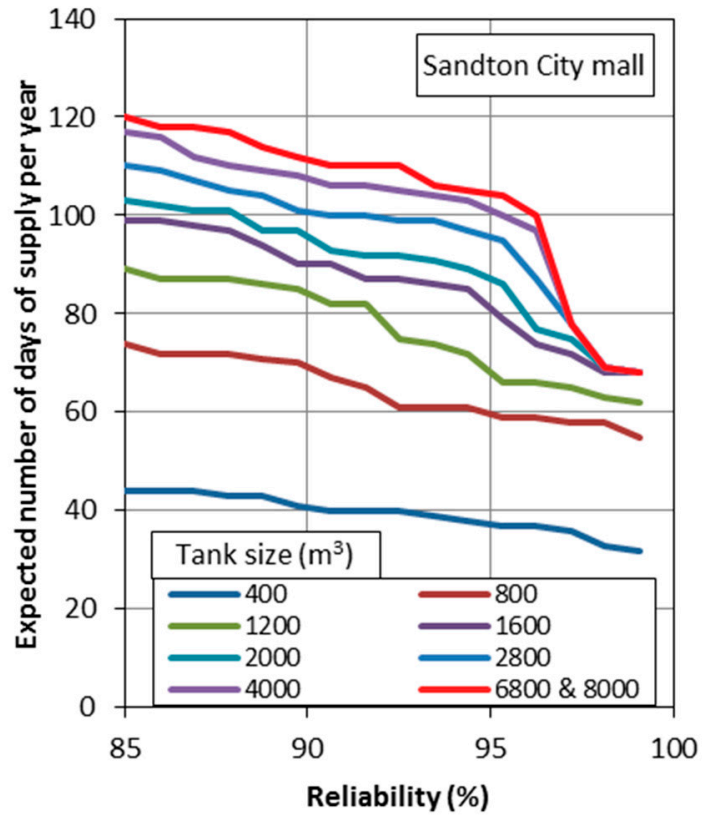

Figure 4 Reliability-supply level relationships for various tank sizes

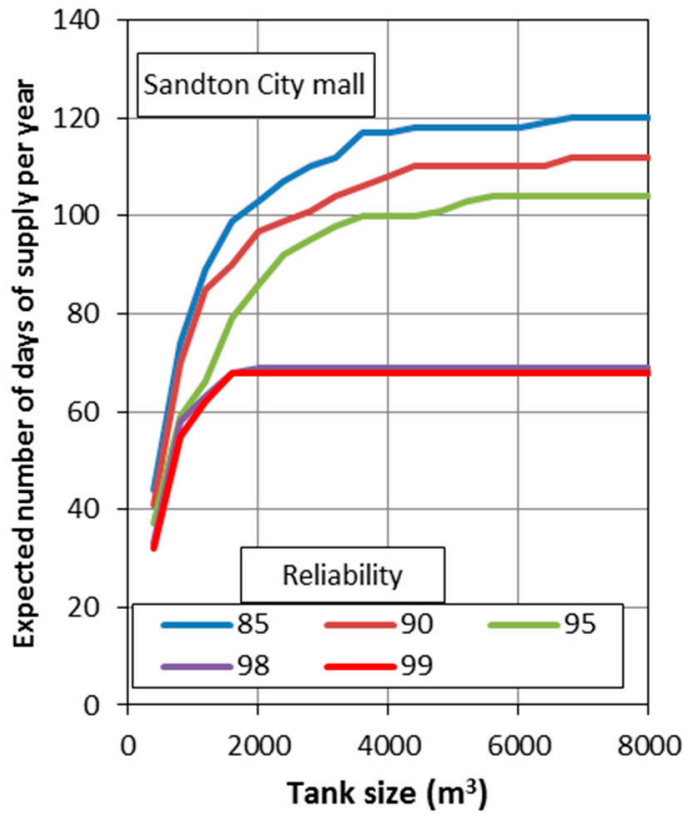

Figure 5 Tank size-supply level relationships for various reliabilities 
Table 2 Expected days of supply per year and optimum tank sizes at various reliabilities.

\begin{tabular}{|c|c|c|c|c|c|c|}
\hline Shopping Centre & Reliability (\%) & 85 & 90 & 95 & 98 & 99 \\
\hline \multirow[t]{2}{*}{ South Gate } & Yield* & 142 & 132 & 122 & 101 & 72 \\
\hline & Storage $^{* *}$ & 4750 & 4250 & 2750 & 1500 & 1500 \\
\hline \multirow[t]{2}{*}{ Braamfontein } & Yield & 12 & 11 & 8 & 7 & 6 \\
\hline & Storage & 130 & 160 & 90 & 130 & 90 \\
\hline \multirow[t]{2}{*}{ Grayston } & Yield & 70 & 61 & 55 & 45 & 40 \\
\hline & Storage & 240 & 165 & 240 & 150 & 105 \\
\hline \multirow[t]{2}{*}{ Norwood } & Yield & 116 & 107 & 95 & 84 & 76 \\
\hline & Storage & 1800 & 3200 & 2000 & 1600 & 1600 \\
\hline \multirow[t]{2}{*}{ Sandton } & Yield & 120 & 112 & 104 & 69 & 68 \\
\hline & Storage & 6800 & 6800 & 5600 & 2000 & 1600 \\
\hline \multirow[t]{2}{*}{ Capricon } & Yield & 242 & 228 & 195 & 172 & 161 \\
\hline & Storage & 3000 & 3750 & 1250 & 1000 & 750 \\
\hline \multirow[t]{2}{*}{ Howard } & Yield & 91 & 84 & 77 & 69 & 63 \\
\hline & Storage & 800 & 550 & 500 & 350 & 300 \\
\hline \multirow[t]{2}{*}{ Willow Bridge } & Yield & 35 & 32 & 28 & 26 & 25 \\
\hline & Storage & 1000 & 600 & 450 & 450 & 450 \\
\hline \multirow[t]{2}{*}{ Tyger Valley } & Yield & 139 & 125 & 117 & 108 & 101 \\
\hline & Storage & 5100 & 3300 & 3000 & 2400 & 2400 \\
\hline \multirow[t]{2}{*}{ Canal Walk } & Yield & 21 & 19 & 16 & 12 & 8 \\
\hline & Storage & 750 & 1125 & 750 & 450 & 300 \\
\hline \multirow[t]{2}{*}{ Mall Of North } & Yield & 65 & 58 & 54 & 44 & 30 \\
\hline & Storage & 4000 & 3250 & 3000 & 2000 & 1250 \\
\hline \multirow[t]{2}{*}{ Savanah } & Yield & 23 & 22 & 18 & 13 & 11 \\
\hline & Storage & 525 & 825 & 825 & 525 & 525 \\
\hline \multirow[t]{2}{*}{ Limpopo } & Yield & 16 & 15 & 11 & 10 & 8 \\
\hline & Storage & 240 & 300 & 240 & 390 & 270 \\
\hline \multirow[t]{2}{*}{ Cycad } & Yield & 23 & 22 & 18 & 13 & 12 \\
\hline & Storage & 160 & 240 & 240 & 160 & 180 \\
\hline \multirow{2}{*}{$\begin{array}{l}\text { Gateway -Reduced } \\
\text { area }\end{array}$} & Yield & 140 & 131 & 108 & 101 & 85 \\
\hline & Storage & 32000 & 24000 & 10000 & 8000 & 6000 \\
\hline \multirow[t]{2}{*}{ Liberty-reduced area } & Yield & 243 & 196 & 162 & 142 & 138 \\
\hline & Storage & 15300 & 9000 & 4500 & 2700 & 1800 \\
\hline \multirow[t]{2}{*}{ Musgrave } & Yield & 41 & 37 & 30 & 27 & 18 \\
\hline & Storage & 1100 & 1000 & 600 & 600 & 400 \\
\hline \multirow{2}{*}{$\begin{array}{l}\text { Phoenix- reduced } \\
\text { area }\end{array}$} & Yield & 153 & 143 & 121 & 104 & 90 \\
\hline & Storage & 7500 & 8500 & 2500 & 1500 & 1500 \\
\hline \multirow[t]{2}{*}{ Granada } & Yield & 46 & 39 & 33 & 27 & 26 \\
\hline & Storage & 255 & 135 & 120 & 90 & 105 \\
\hline
\end{tabular}




\section{Formulating Generalized Storage-Yield-Reliability Relationships}

Although the study was confined to 19 shopping centres located in 4 regions of South Africa, it was probable that the results from this analysis could be used to formulate generalized relationships for quantifying the rainwater harvesting potential and optimum tank sizes for other shopping centres and other rainwater harvesting systems of similar characteristics. Results from simulation of rainwater harvesting systems have previously been used to generalize rainwater harvesting system sizing and assessment $[26,27,35]$ although these studies did not include within-year-system performance and reliability as in the current analysis. A study of the rainwater harvesting potential of schools in three regions of South Africa [15] obtained generalized relationships between the supply to demand ratio and proportion of time that the supply meets demand and this would also be expected to exist for shopping centre systems. Additionally, the tank size to demand ratio would intuitively be expected to relate with the proportion of time that supply meets demand. Generalization would be more effective if all the variables involved are expressed as dimensionless ratios and relationships among the variables defined by equations 5 to 7 were therefore sought after.

$$
\text { Ratio of supply to demand }=R_{S D}=\frac{\text { Average Supply }}{\text { Average demand }}=\frac{\eta A \bar{P}}{\overline{D_{t}}}
$$

$$
\begin{aligned}
& \begin{array}{l}
\text { Proportion of days supplied } \\
\text { per year for reliability } r
\end{array}=S_{P-r}=\frac{\text { Expected number of days of supply per year for reliabilityr }}{365.25 \text { days per year }} \\
& \text { Ratio of tank size for reliability } \\
& r \text { to volume of annual demand }=R_{T D-r}=\frac{\text { optimum tank size for reliability } r}{\text { Volume of average annual demand }\left(\overline{D_{t}} \times 365.25 \text { days }\right)}
\end{aligned}
$$

Where $\boldsymbol{\eta}$ is the efficiency of rainwater collection into the tank, $A$ is the vertical projection of the roof area, $\bar{P}$ is the average daily rainfall, $\overline{D_{t}}$ is the average daily demand, and $r$ (in $S_{P-r}$ and $R_{T D-r}$ ) is the reliability of supply.

The non-linear power law model was found to fit the relationships between $R_{S D}$ and $S_{P-r}$ best at the 5 reliabilities of 85, 90, 9598 and $99 \%$ as shown on Figure 6. Generalization that would include reliability within the power models was now sought by finding out if satisfactory relationships existed between the parameters of the power models and reliability. Figure 7 shows the relationships between these parameters and reliability revealing well-fitting power law models. Figures 8 and 9 show the respective relationships between and $S_{P-r}$ and $R_{T D-r}$ and the parameters of the power model with reliability. The correlations between $S_{P-r}$ and $R_{T D-r}$ were lower than those between $R_{S D}$ and $S_{P-r}$ but they were still considered satisfactory.

The generalized model of the rainwater harvesting system could therefore be summarized as:

$$
\begin{aligned}
& S_{p-r}=a R_{S D}^{b} \quad a=1.1428(1-r)^{0.1514} \quad b=1.2416(1-r)^{-0.037} \quad 0.85 \leq r \leq 0.99 \\
& R_{T D-r}=c S_{p-r}^{d} c=1.4365(1-r)^{0.5703} \quad d=2.0065(1-r)^{0.2131} \quad 0.85 \leq r \leq 0.99
\end{aligned}
$$

These equations and their graphical form on Figure 10 can be used to size hydrologically optimum rainwater harvesting systems and to assess existing ones if they are hydrologically optimum. In reality, this may not always be the case as other factors including economics or sizes of commercially available tanks influence system sizing. Furthermore, even if an optimal system was initially installed, changes in demand or/and supply available (e.g. due to climate change or rainwater collection area) would render it non-optimal. There was therefore the need to formulate generalization that would enable sizing and assessment of hydrologically non-optimal systems. 

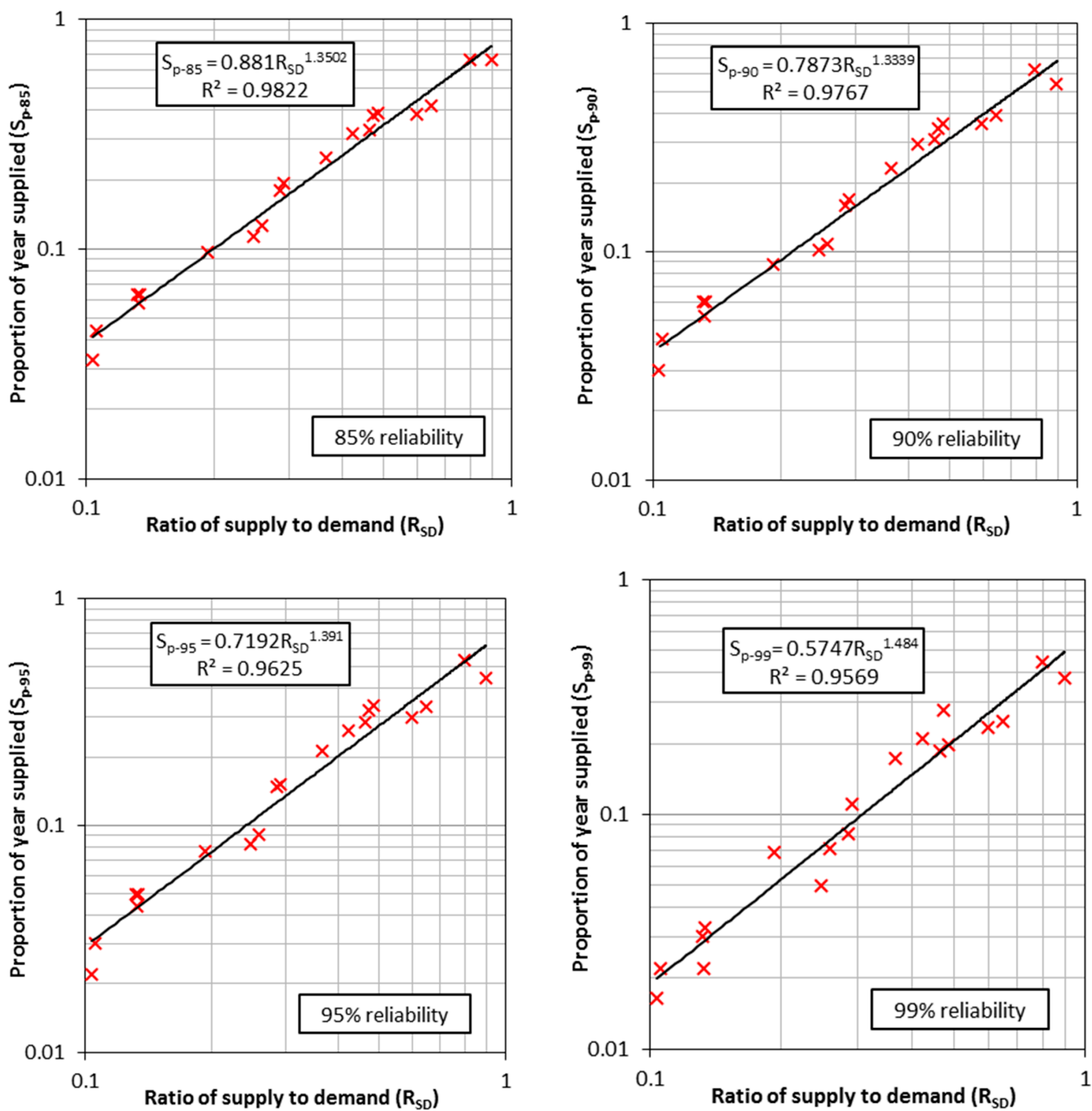

Figure 6 Generalized relationship between supply, demand and level of supply.
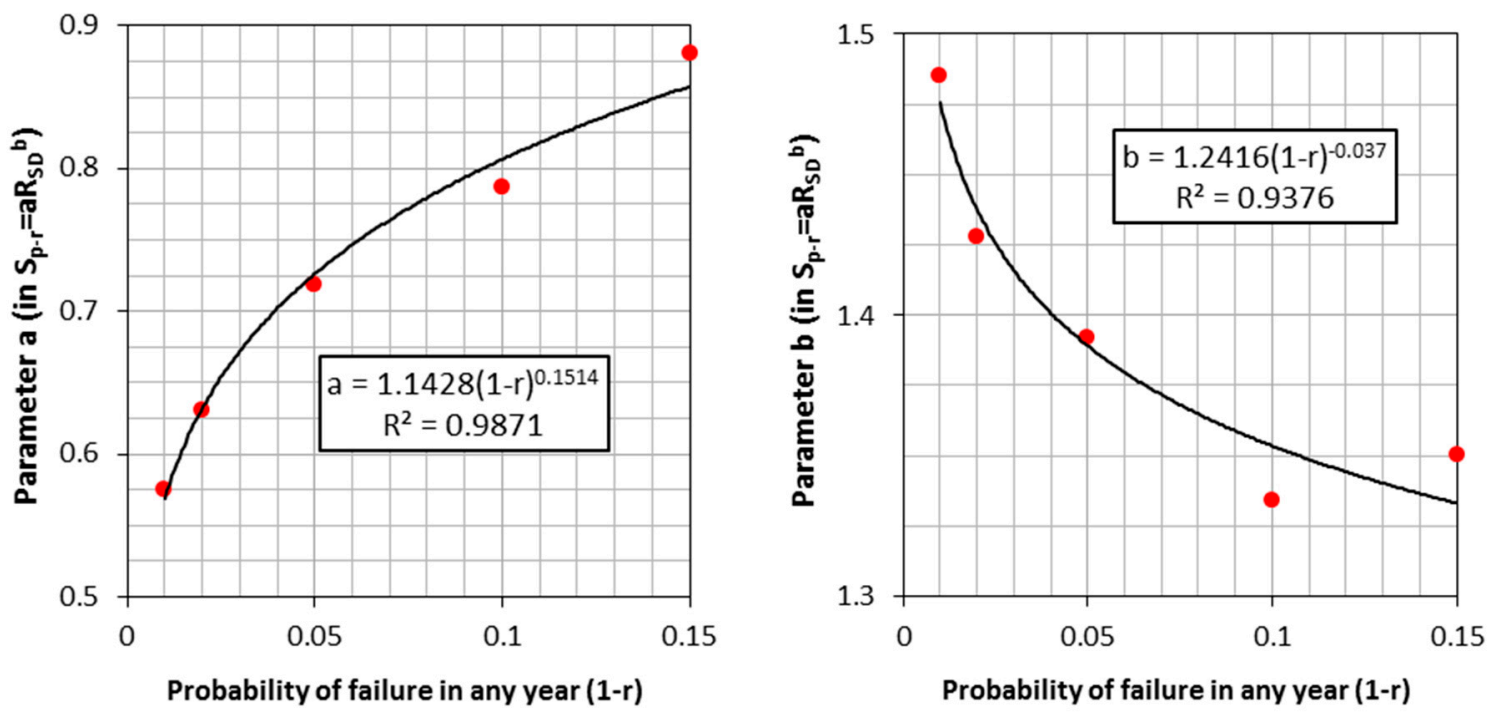

Figure 7 Relationships between supply level and supply-to-demand ratio model parameters with reliability 

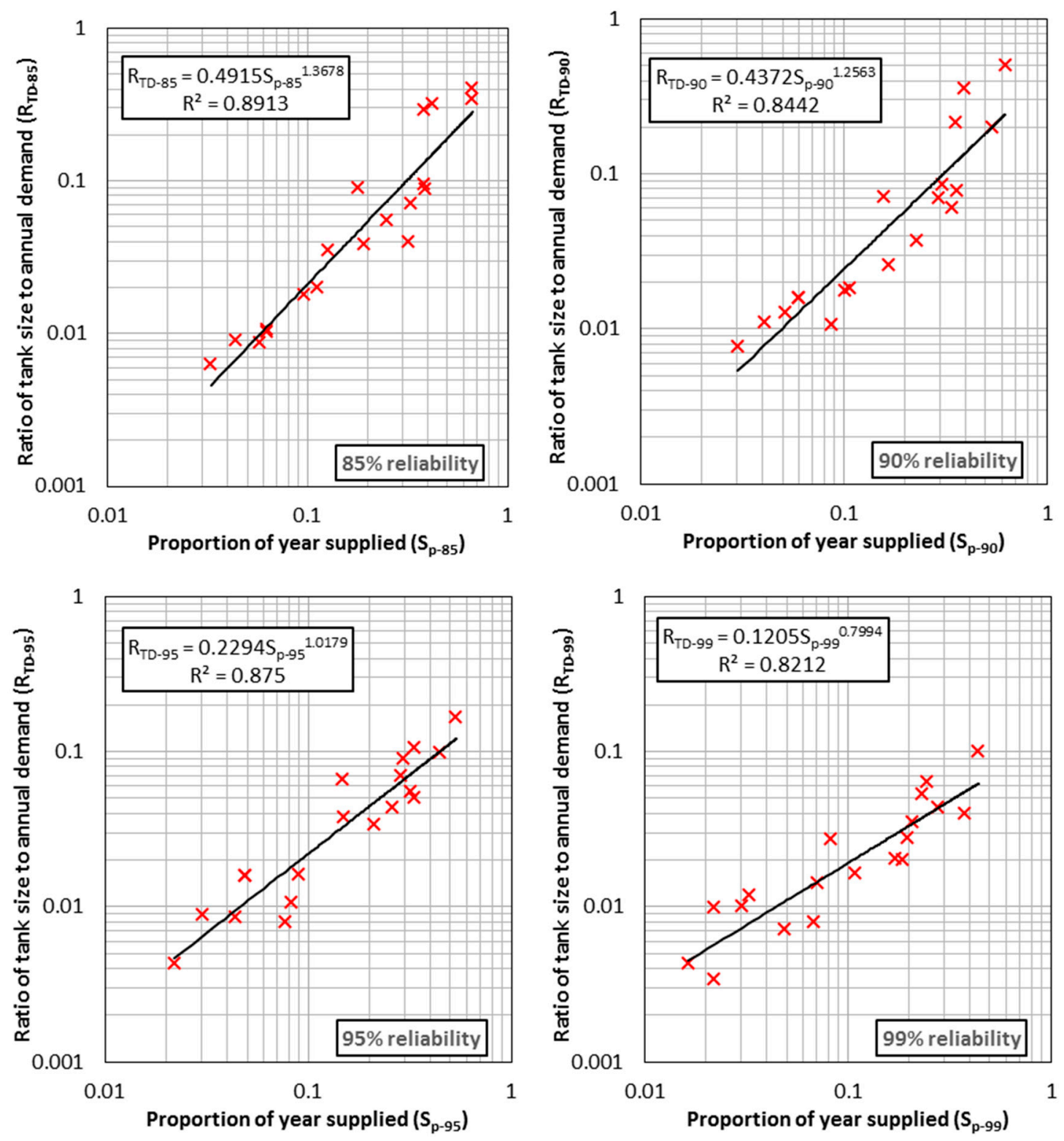

Figure 8 Generalized relationships between level of supply, demand and tank size.
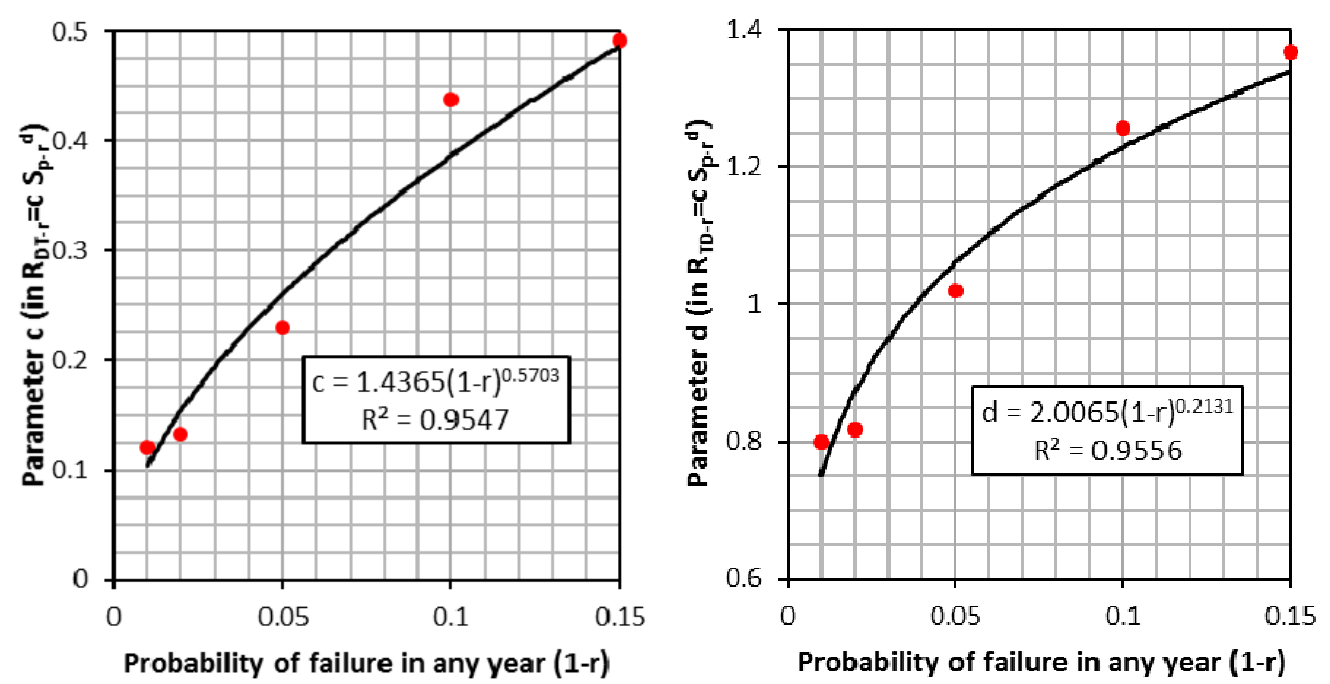

Figure 9 Relationships between tank size to demand ratio model parameters with reliability 

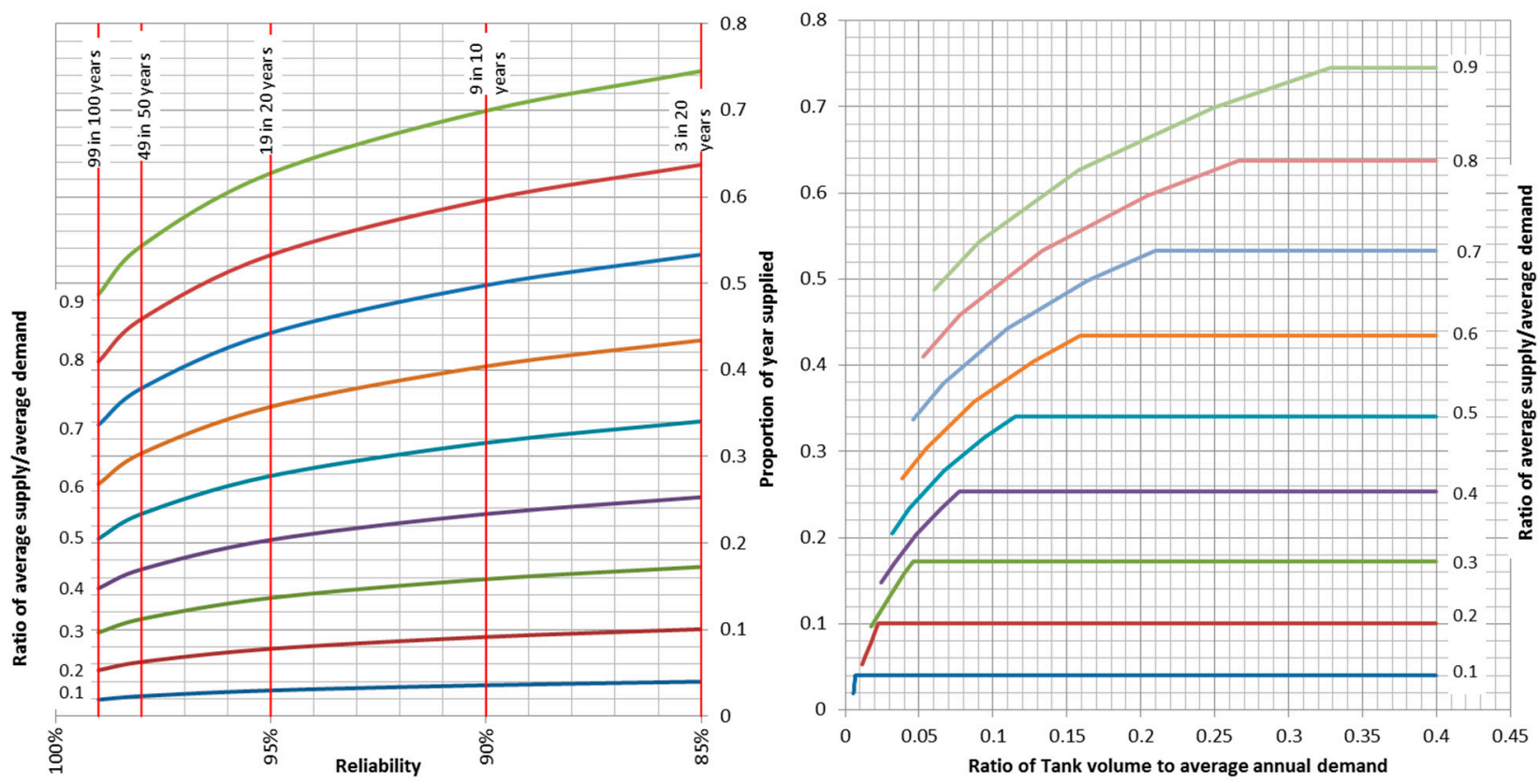

Figure 10 Graphical presentation of generalized model for sizing and assessing rainwater harvesting system performance.

For the range of reliabilities applied $(85-99 \%)$, a reasonably linear relationship between reliability and proportion of year supplied (yield) was found to exist for a given storage as illustrated on Figure 11 for one of the shopping centres. If a generalized relationship between the slope of this line ( $S_{L R}$ in Figure 11) and any of the dimensionless ratios defined in equations 5 to 7 could be obtained, then the relationship between yield and reliability within the non-optimal space could be generalized. This is illustrated on Figure 12 for a target reliability $\boldsymbol{r}_{t}$ and proportion of supply $\boldsymbol{S}_{p-r t}$. It was observed that the slopes $S_{L R}$ generally increased with yield $S_{p-r}$ and generalized relationships between these two variables were therefore sought. Slopes $S_{L R}$ were therefore obtained for four ranges of reliability: 85-90, 85-95, 85-98 and 85- 99\% for the simulation runs of all 19 shopping centres using least squares fitting. Model fits between $S_{L R}$ and $S_{p-r}$ were then investigated on spreadsheet.

Figure 13 shows the best fitting power law models between the slope $S_{L R}$ and the optimal yield (proportion of year supplied) $S_{p-r}$ for the four ranges of reliability while Figure 14 shows the relationships obtained between the parameters of the power law model and the upper limit of the reliability ranges (which is the reliability at the hydrologic optimum). As for the previous generalized relationships, reasonably good fits were obtained. Equations 10 and 11 define this model and combined application of this model with the other two (equations 8 and 9) enables the sizing and assessment of rainwater harvesting system performance for both hydrologically optimal and nonoptimal rainwater harvesting systems. An example problem now illustrates how this could be done.

$S_{L S}=e S_{p-r}^{f} e=0.6629(1-r)^{-0.184} f=-1.7615 r+2.3725 \quad 0.85 \leq r \leq 0.99$

$S_{p-r_{t}}=S_{p-r}+\left(r-r_{t}\right) S_{L S} \quad r \geq r_{t}$ 


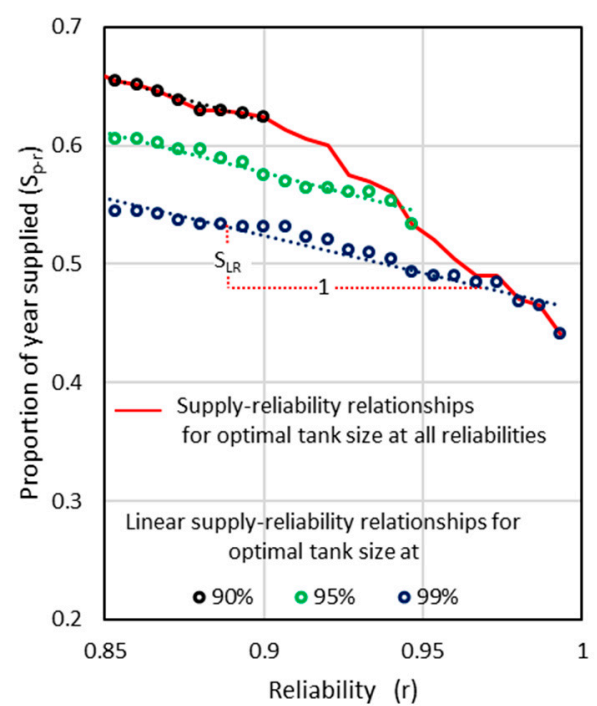

Figure 11 Linear supply level - reliability relationship forgiven tank size.
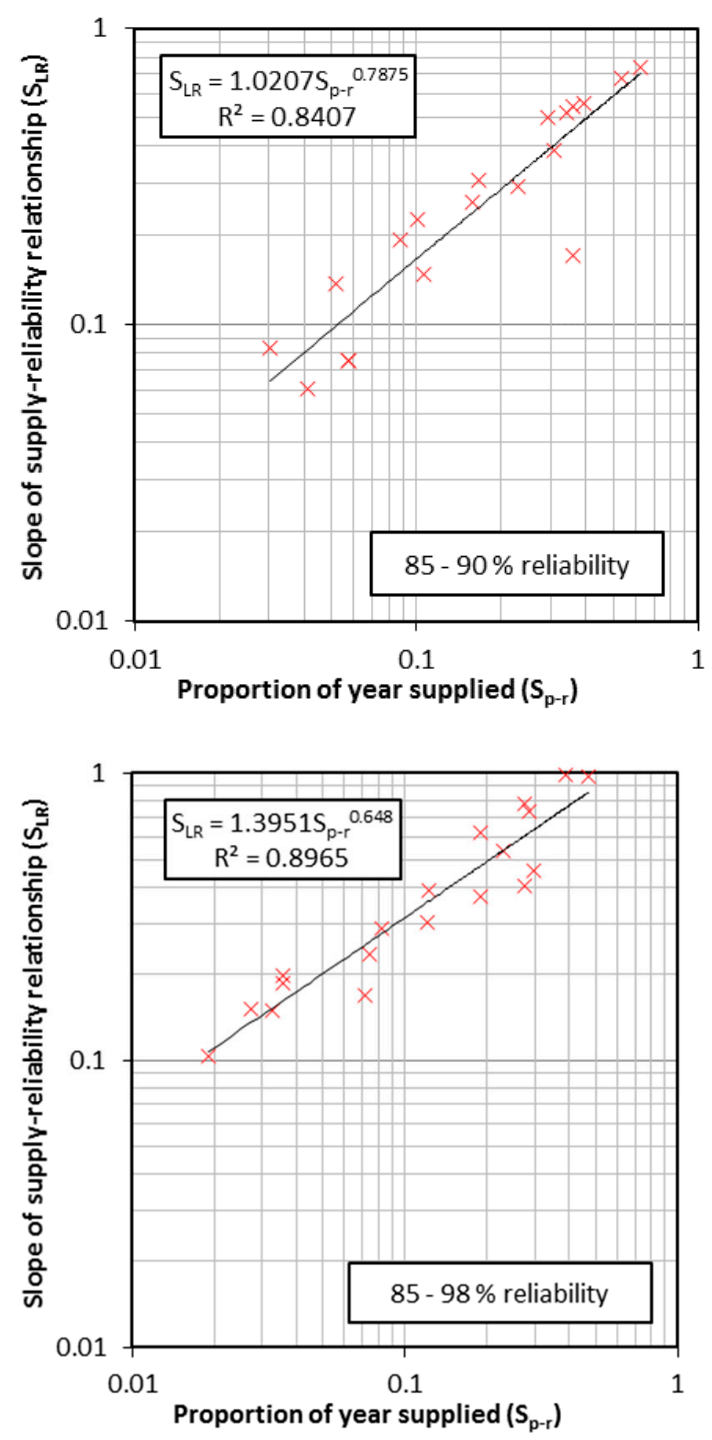

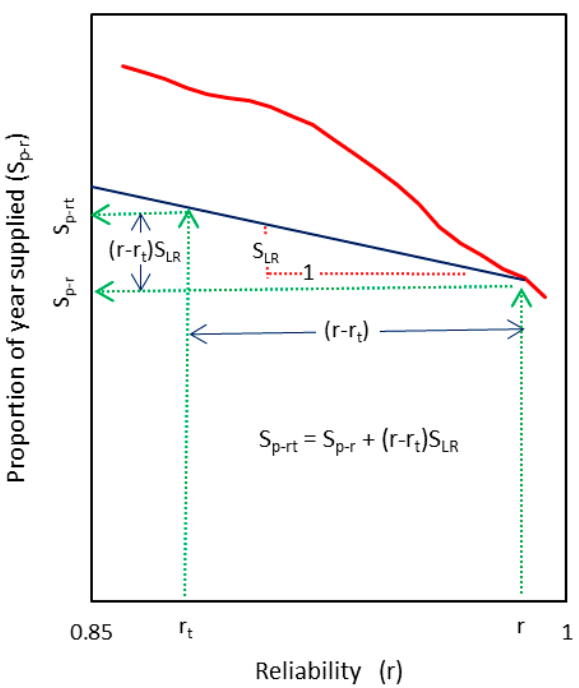

Figure 12 Determination of proportion of supply for non-optimal system.
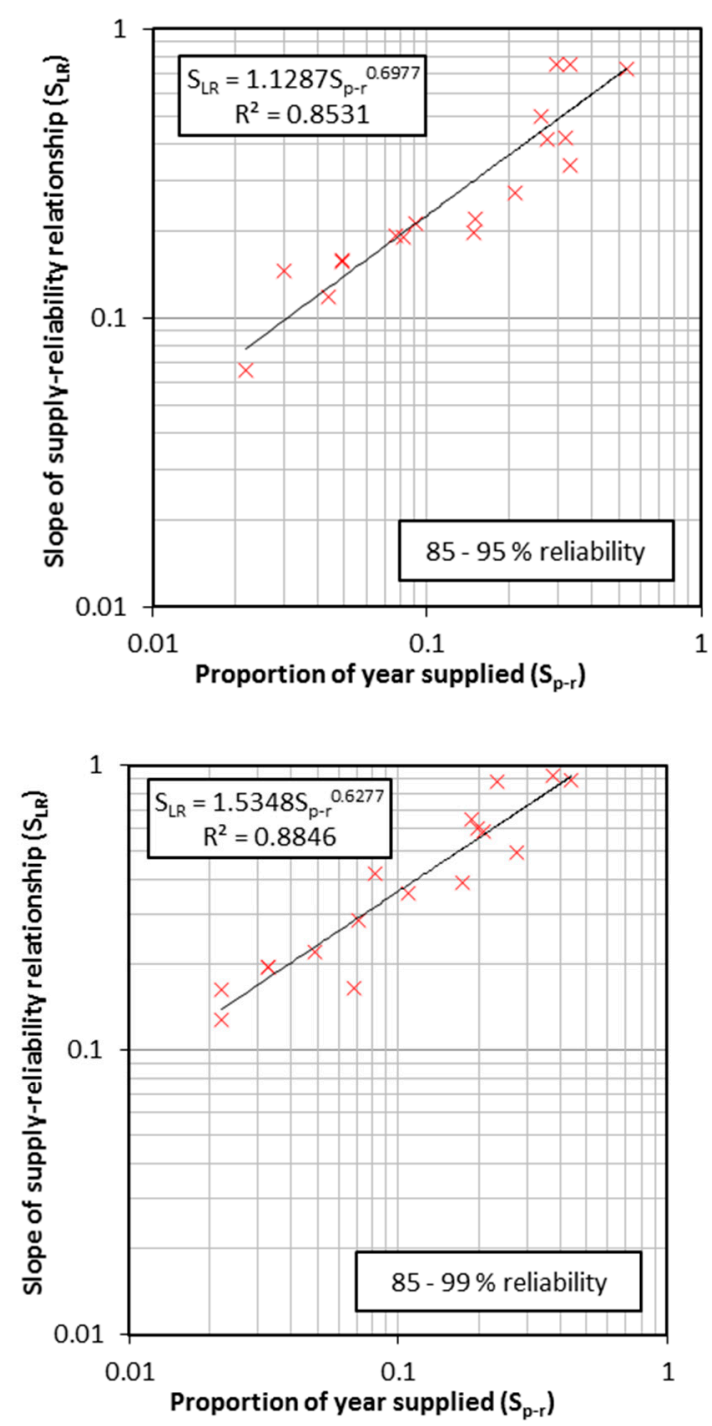

Figure 13 Relationships between reliability- level of supply slope and proportion of supply 

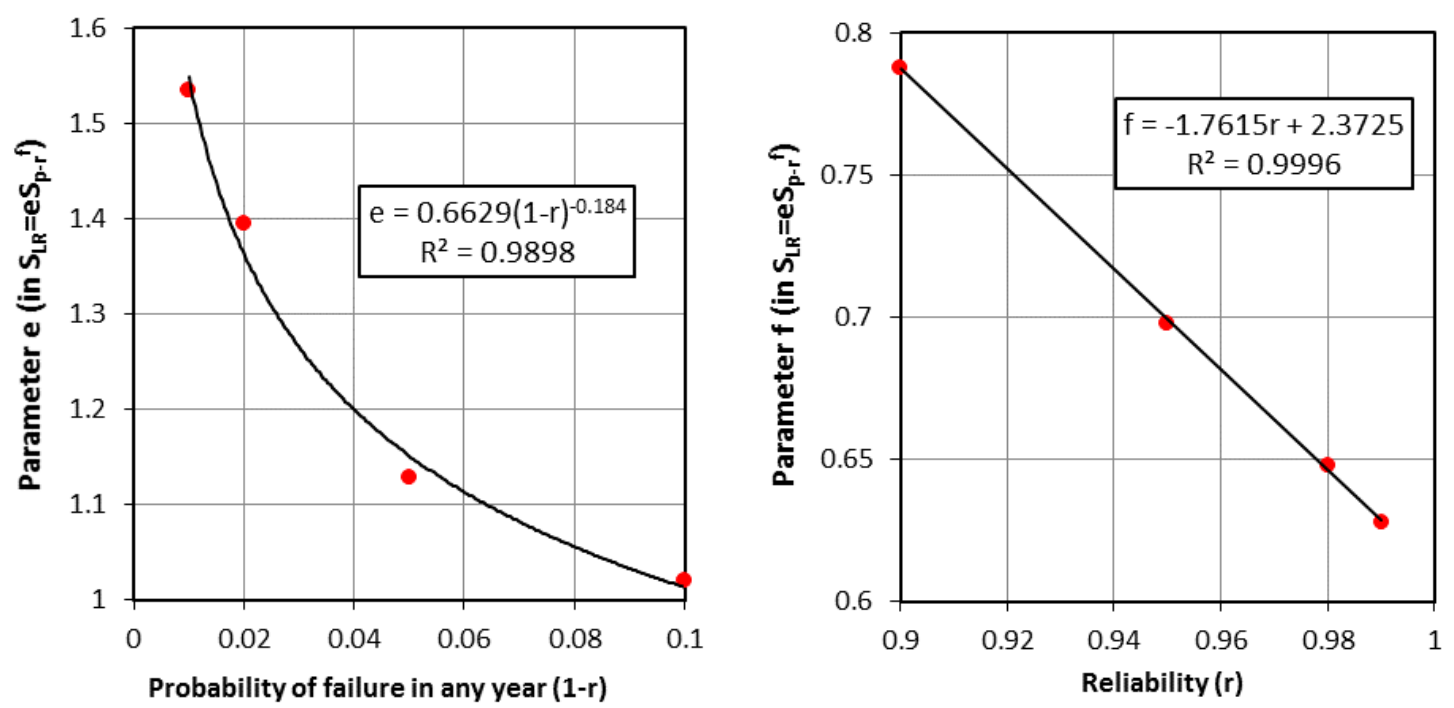

Figure 14 Relationship between parameters of slope-supply level model and reliability.

\section{Example-Applying Generalized Models to determine Storage and assess System Performance}

A shopping centre with a retail area of $50000 \mathrm{~m}^{2}$ is proposed for an area with a mean annual rainfall (MAR) of $940 \mathrm{~mm} /$ year and the total rainfall collection area that includes the out-door parking will be $100000 \mathrm{~m}^{2}$ and will have a rainwater collection efficiency of $80 \%$. The demand is estimated as $2.5 \mathrm{~m}^{3} / \mathrm{m}^{2}$ of retail area/year. What would be the expected number of days of supply for the shopping centre at a reliability of $98 \%$ ? What size of tank would be required for this? It is projected that climate change could reduce the MAR in the area to $700 \mathrm{~mm} /$ year and increase the average demand to $2.8 \mathrm{~m}^{3} / \mathrm{m}^{2} /$ year as air conditioning water demand increases with temperature. How would this impact on the performance of the rainwater harvesting system?

For the current conditions, the ratio of average supply available to average demand

$R_{S D}=\frac{100000 m^{2} \times \frac{940 \mathrm{~mm} / \text { year }}{1000 \mathrm{~mm} / \mathrm{m}} \times 0.8}{2.5 \mathrm{~m}^{3} / \mathrm{m}^{2} / \text { year } \times 50000 \mathrm{~m}^{2}}=0.60$

The expected proportion of supply per year is obtained applying equation 8 for a reliability of $98 \%$ (0.98). For $r=0.98, a=1.1428(1-0.98)^{0.1514}=0.632$ and $b=1.2416(1-0.98)^{-0.037}=1.435$

Therefore $S_{p-0.98}=0.632 \times 0.60^{1.435}=0.305$

Therefore the expected number of days of supply $=0.305 \times 365.25=111$ days per year.

The ratio of tank size to average annual demand is obtained from equation 9. For $r=0.98$, $c=1.4365(1-0.98)^{0.703}=0.154$ and $d=2.0065(1-0.98)^{0.2131}=0.872$

Therefore $R_{T D-0.98}=0.154 \times 0.305^{0.872}=0.0548$

The required size of tank is therefore $=0.0548 \times\left(2.5 \mathrm{~m}^{3} / \mathrm{m}^{2} /\right.$ year $\left.\times 50000 \mathrm{~m}^{2}\right)=6847 \mathrm{~m}^{3}$.

If due to climate change the MAR reduces to $700 \mathrm{~mm} / \mathrm{year}$ and the demand increases to $2.8 \mathrm{~m}^{3} / \mathrm{m}^{2} /$ year, the new ratio of average available supply to demand

$R_{S D}=\frac{100000 \mathrm{~m}^{2} \times \frac{700 \mathrm{~mm} / \text { year }}{1000 \mathrm{~mm} / \mathrm{m}} \times 0.8}{2.8 \mathrm{~m}^{3} / \mathrm{m}^{2} / \text { year } \times 50000 \mathrm{~m}^{2}}=0.40$

The tank size of $6847 \mathrm{~m}^{3}$ that was optimal for $R s D=0.6$ at $98 \%$ reliability is now optimal at a different reliability (and not $98 \%$ ) since the $R S D$ value has changed. In order to use equation 8 to determine the expected proportion of supply per year, the reliability for which the tank volume of $6847 \mathrm{~m}^{3}$ is optimal for $R_{S D}=0.40$ is required. Since $\boldsymbol{R}_{T D-r}$ can be obtained for the new conditions, $\boldsymbol{R}_{S D}$ is known, and $\boldsymbol{S}_{p-r}$ needs to equal in equations 8 and 9, the optimal reliability $r$ and $S_{p-r}$ for the climate change scenario can be obtained simultaneously using the two equations ( 8 and 9 ). For this scenario, 
$R_{T D-r}=\frac{6847 m^{3}}{2.8 m^{3} / m^{2} \times 50000 m^{2}}=0.0489$

From equation 9,

$S_{p-r}=\left(\frac{R_{T D-r}}{c}\right)^{\left(\frac{1}{d}\right)}$

From equations 8 and 12,

$S_{p-r}=\left(\frac{R_{T D-r}}{c}\right)^{\left(\frac{1}{d}\right)}=a R_{S D}^{b}$

Therefore

$\left.\left(\frac{0.0489}{1.4365(1-r)^{0.5703}}\right)^{\left(\frac{1}{2.0065(1-r)^{0.2131}}\right)}=1.1428(1-r)^{0.1514} \times 0.4^{\left(1.2416(1-r)^{-0.037}\right.}\right)$

This obtains $r=0.948$ and $S_{p-0.948}=1.1428(1-0.948)^{0.1514} \times 0.4^{\left(1.2416(1-0.948)^{-0.037}\right)}=0.205$ The expected number of days of supply at $94.8 \%$ reliability $=0.205 \times 365.25=75$ days per year.

This expected yield is lower than that for the current climate which was found to be 111 days per year at a reliability of $98 \%$. A more complete assessment of the effect climate change would be achieved by comparing the expected yields for the complete range of probabilities (85-99\%). This is achieved by using equations 10 and 11 for the hydrologically non-optimal ranges that the rainwater harvesting system could be operated at. For the normal climate, the slope $S_{L R}$ at $98 \%$ reliability is obtained as 0.632 using equation 10 and using this slope in equation 11 this gives $S_{p-95}, S_{p-90}$ and $S_{p-85}$ values of $0.321,0.345$ and 0.364 respectively. For the climate change scenario, $S_{L R}$ at $94.8 \%$ reliability is obtained as 0.375 and $S_{p-90}$ and $S_{p-85}$ are obtained as 0.218 and 0.225 respectively. Figure 15 shows the respective plots of reliability versus proportion of supply for the two cases.

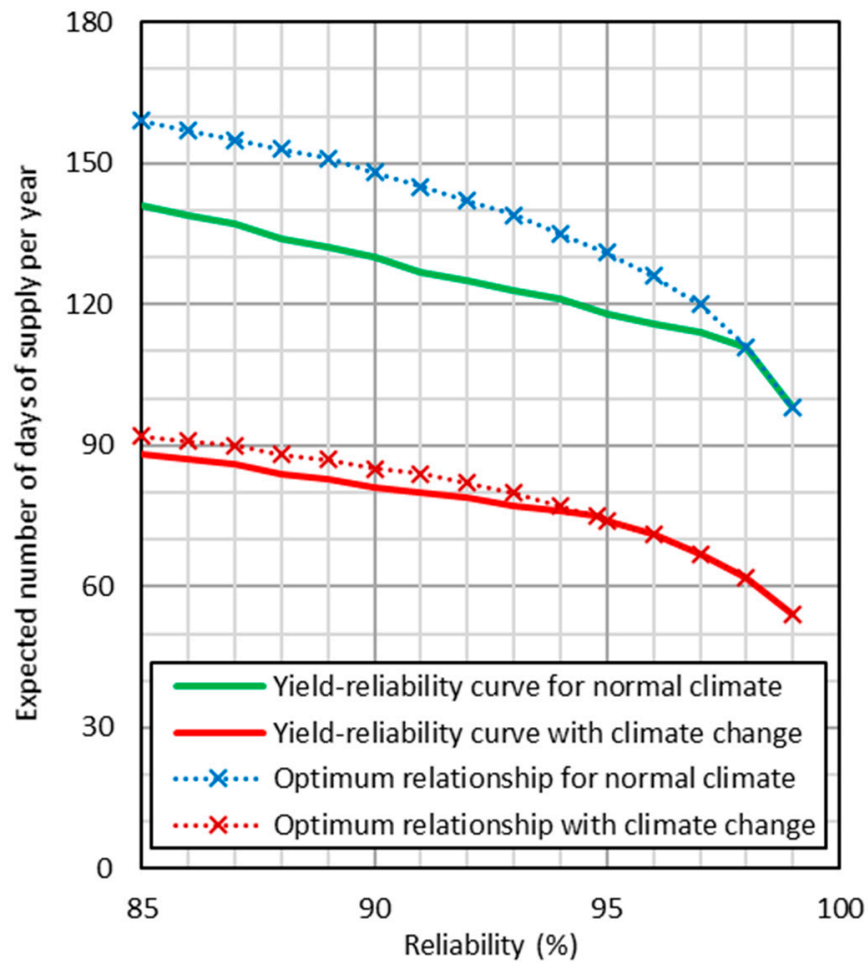

Figure 15 Yield -reliability relationships for normal and climate change scenario 


\section{Discussion and Conclusions}

Generalized dimensionless relationships for sizing and assessing the performance of rainwater harvesting systems of shopping centres in South Africa have been developed using the results of daily-time step simulations of the rainwater harvesting systems of 19 shopping centres. One generalized relationship is between the ratio of supply to demand, the yield and the reliability while another is between the ratio of optimal tank size to annual demand, the yield and reliability. These two relationships are based on simulation results for the hydrologically optimum combination of yield, reliability and storage. This optimum combination is obtained by finding out the minimum storage (tank size) at which yield levels to its highest value for the specified reliability. Rainwater harvesting systems may however not necessarily be designed to be hydrologically optimum as there are several other factors including economic considerations, set roof areas for rainwater collection and the commercially available tank sizes that are relevant to rainwater harvesting system design. An additional generalization between the slope of the reliability-yield relationship and the yield (for a hydrologically optimal system) is therefore developed to enable sizing and assessment of system performance of hydrologically non-optimal systems. The generalization is carried out at two levels; firstly by obtaining relationships of the variables at reliabilities of 85, 90, 95, 98 and 99\% (Figures 6, 8 and 13) and secondly by obtaining relationships between the parameters of these models and reliability (Figures 7, 9 and 14). All the first level generalizations and five of these second level ones fit best to power law models while one second level generalization fits best to a linear model. All the model fits have high correlation coefficients that exceed 0.8 and average 0.92 . An example is provided to demonstrate the application of the generalized relationships for tank sizing and for assessing the effect of a reduction in average supply available and increase in demand (that for example climate change might cause) on rainwater harvesting system performance.

In comparison to previous studies that included generalization of rainwater harvesting system sizing [26,27,35], the current analysis incorporates within-year yield and reliabilities comprehensively and is applicable to regions that have low rainfalls with large temporal variability. Rainwater harvesting systems in such regions are more likely to exhibit within-year rather than overyear storage behavior and within-year yield is also likely to be temporally highly variable. Initial analysis of the rainwater harvesting potential in the current study revealed that using very large storages could enable over-year storage behavior for three of the centres in the high rainfall Kwa Zulu Natal region of South Africa. For such systems reliability could be assessed comprehensively using monthly time step multiple systems simulations with ensembles of stochastic rainfalls (and not a single historic series) as inputs. Ndiritu and Nyaga [39] have formulated a stochastic rainfall model could be applied for this.

Although these centres used in the analysis are located in four specific regions of South Africa (Gauteng, Kwa Zulu Natal, Cape Town and Limpopo), the satisfactory generalization reveals that any distinct rainfall characteristics that might exist in any region do not significantly affect the dimensionless relationships obtained. These relationships are therefore most likely applicable to other regions of South Africa and probably beyond. Satisfactory model fits were obtained but the relationships are moderately scattered and additional analysis with a larger number of rainfall stations could enable the generation of confidence intervals for the generalized models. In addition, the influence of the distribution of demand on the modelling within the year could also be investigated

Author Contributions: Ndiritu JG conceived the concepts and Ndiritu J G, Guliwe M and Moodley Y designed the experiments; Moodley Y, Guliwe M and Ndiritu J G performed the experiments; Ndiritu J G, Guliwe M and Moodley Y analyzed the data; Ndiritu J G wrote the paper.

Conflicts of Interest: The authors declare no conflicts of interest. 


\section{References}

1. UNESCO. The United Nations World Water Development Report 3: Water in a Changing World.; 2009. doi:10.1017/CBO9781107415324.004.

2. $\quad$ UNESCO. World Water Development Report Volume 4: Managing Water under Uncertainty and Risk. Vol 1.; 2012. doi:10.1608/FRJ-3.1.2.

3. Pinzon TM. Modelling and sustainable management of rainwater harvesting in urban systems. Unpublished PhD thesis: Institute of Environmental Science and Technology (ICTA) at Universitat Autònoma de Barcelona (UAB). 2012.

4. O'Brien O. Domestic water demand for consumers with rainwater harvesting systems. Unpublished MSc thesis: Department of Civil Engineering, Division of Water and Environmental Engineering, Stellenbosch University. 2014.

5. Dobrowksy PH, Mannel D, De Kwaadsteniet M, Prozesky H, Khan W, Cloete TE. Quality assessment and primary uses of harvested rainwater in Kleinmond, South Africa. Water SA. 2014;40(3):401-406. doi:10.4314/wsa.v40i3.2.

6. Abbott SE, Douwes J, Caughley BP. A survey of the microbiological quality of roof-collected rainwater of private dwellings in New Zealand. In: WATER 2006 INTERNATIONAL CONFERENCE, Auckland. ; 2006:1-24.

7. Evans CA, Coombes PJ, Dunstan RH. Wind, rain and bacteria: The effect of weather on the microbial composition of roof-harvested rainwater. Water Res. 2006;40(1):37-44. doi:10.1016/j.watres.2005.10.034.

8. Chang M, McBroom MW, Scott Beasley R. Roofing as a source of nonpoint water pollution. $J$ Environ Manage. 2004;73(4):307-315. doi:10.1016/j.jenvman.2004.06.014.

9. Evison L, Sunna N. Microbial regrowth in household water storage tanks. J Am Water Work Assoc. 2001;93(9):85-94.

10. van der Sterren M, Rahman A, Dennis GR. Quality and Quantity Monitoring of Five Rainwater Tanks in Western Sydney, Australia. J Environ Eng. 2013;139(3):332-340. doi:10.1061/(ASCE)EE.19437870.0000614.

11. Sazakli E, Alexopoulos A, Leotsinidis M. Rainwater harvesting, quality assessment and utilization in Kefalonia Island, Greece. Water Res. 2007;41(9):2039-2047. doi:10.1016/j.watres.2007.01.037.

12. Still, D., Erskine, S., Walker, N. \& Hazelton D. The Status and Use of Potable Water Efficient Devices in the Domestic and Commercial Environments. Gezina, Gauteng, South Africa: Water Research Commission. WRC Project No. K5/1606, 1-36.; 2007.

13. Mwenge Kahinda J, Taigbenu AE, Boroto JR. Domestic rainwater harvesting to improve water supply in rural South Africa. Phys Chem Earth, Parts A/B/C. 2007;32(15):1050-1057. doi:10.1016/j.pce.2007.07.007.

14. Mwenge Kahinda J, Taigbenu AE, Boroto RJ. Domestic rainwater harvesting as an adaptation measure to climate change in South Africa. Phys Chem Earth. 2010;35(13-14):742-751. doi:10.1016/j.pce.2010.07.004.

15. Ndiritu JG, McCarthy S, Tshirangwana N. Probabilistic assessment of the rainwater harvesting potential of schools in South Africa. Proc Int Assoc Hydrol Sci. 2014;364(June):435-440. doi:10.5194/piahs-364-435-2014.

16. Prinsloo DA. Classification and Hierarchy of Retail Facilities in South Africa. Urban Studies. http://www.urbanstudies.co.za/wp-content/uploads/2014/07/New-Retail-Classification-2010.pdf. Published 2012. Accessed August 6, 2015.

17. Prinsloo DA. Benchmarking the South African Shopping Centre Industry International and Local Trends. South African Council of Shopping Centres: Shopping Centre Directory.; 2013.

18. Lynch S. The Development of a Raster Database of Annual, Monthly and Daily Rainfall for Southern Africa. Pretoria, ZA: Water Research Commission, WRC Report No. 1156/0/1.; 2003.

19. CSIR. Guidelines for Human Settlement Plannning and Design. Vol 2.; 2005.

20. Saunders A. Shopping Centre Water Efficiency Report Prepared by HFM Asset Management.; 2012.

21. McMahon, T. A. \& Adeloye AJ. Water Resources Yield. Water Resources Publications; 2005.

22. Santos C, Taveira-Pinto F. Analysis of different criteria to size rainwater storage tanks using detailed methods. Resour Conserv Recycl. 2013;71:1-6. doi:10.1016/j.resconrec.2012.11.004.

23. Ndiritu J, Odiyo JO, Makungo R, Ntuli C, Mwaka B. Yield-reliability analysis for rural domestic water supply from combined rainwater harvesting and run-of-river abstraction. Hydrol Sci J. 2011;56(2):238248. doi:10.1080/02626667.2011.555766.

24. Ward S, Memon FA, Butler D. Rainwater harvesting: Model-based design evaluation. Water Sci Technol. 2010;61(1):85-96. doi:10.2166/wst.2010.783. 
25. Su M-D, Lin C-H, Chang L-F, Kang J-L, Lin M-C. A probabilistic approach to rainwater harvesting systems design and evaluation. Resour Conserv Recycl. 2009;53(7):393-399. doi:10.1016/j.resconrec.2009.03.005.

26. Liaw $\mathrm{CH}, \mathrm{Chiang}$ YC. Dimensionless analysis for designing domestic rainwater harvesting systems at the regional level in Northern Taiwan. Water (Switzerland). 2014;6(12):3913-3933. doi:10.3390/w6123913.

27. Notaro V, Liuzzo L, Freni G. Reliability Analysis of Rainwater Harvesting Systems in Southern Italy. Procedia Eng. 2016;162:373-380. doi:10.1016/j.proeng.2016.11.077.

28. Mashau F (2006). Rainwater harvesting for multiple uses in Siloam Village of Limpopo Province, South Africa. Unpublished Honours research dissertation, University of Venda, South Africa. 2006.

29. Berwanger H, Ghisi E. Investment feasibility analysis of rainwater harvesting in the city of Itapiranga, Brazil. Int J Sustain Hum Dev. 2014;2:104-114.

30. Ghisi E, Tavares D d F, Rocha VL. Rainwater harvesting in petrol stations in Bras??lia: Potential for potable water savings and investment feasibility analysis. Resour Conserv Recycl. 2009;54(2):79-85. doi:10.1016/j.resconrec.2009.06.010.

31. Hashimoto T, Loucks DP, Stedinger JR. Robustness of water resources systems. Water Resour Res. 1982;18(1):21-26. doi:10.1029/WR018i001p00021.

32. Basson, M.S., Allen, R.B., Pegram, G.G.S., Van Rooyen J. Probabilistic Management of Water Resource and Hydropower Systems. Water Resources Publications; 1994.

33. Basson MS, van Rooyen JA. Practical Application of Probabilistic Approaches to the Management of Water Resource Systems. J Hydrol. 2001;241(1-2):53-61. doi:10.1016/S0022-1694(00)00367-X.

34. Ndiritu J, Odiyo J, Makungo R, et al. Development of probabilistic operating rules for Hluhluwe Dam, South Africa. Physics and Chemistry of the Earth. 2016.

35. Fewkes A. Modelling the performance of rainwater collection systems: towards a generalised approach. Urban Water. 2000;1(1999):323-333. doi:10.1016/S1462-0758(00)00026-1.

36. W W. A statistical theory of strength of materials. Ing Vetensk Akad Handl. 1939;151:1-45.

37. Makkonen L. Plotting positions in extreme value analysis. J Appl Meteorol Climatol. 2006;45(2):334340. doi:10.1175/JAM2349.1.

38. Cunnane C. Unbiased plotting positions - a review. J Hydrol. 1978;37:205-222.

39. Ndiritu J; Nyaga J. A Non-Parametric Multi-Site Stochastic Rainfall Model with Applications to Climate Change, WRC Report No. 2148/1/13.; 2014. 